Literatura y Lingüística $\mathrm{N}^{\circ} 26$

ISSN 0716-5811 / pp. 29-46

\title{
Del latín al castellano o de las humanidades clásicas a las humanidades modernas en el siglo XIX chileno*
}

\author{
Edda Hurtado*
}

\section{Resumen}

Nos interesa aproximarnos al estudio del predominio de la enseñanza de la lengua y literatura latinas en el marco del Chile decimonónico, cuya matriz cultural se fraguó en un espacio intelectual que parte en la década de 1840 con una primacía que modula el sistema educativo nacional hasta la década de 1880, periodo en el que progresivamente el positivismo y la filología -sin exención de polémicas culturales, políticas e incluso religiosas- desplazaron el modelo de las humanidades clásicas, instalando en su lugar el estudio del Castellano.

Palabras clave: literatura, educación, latín, castellano, siglo XIX chileno.

\section{From Latin to Spanish or from classical humanities to modern humanities in the Chilean $19^{\text {th }}$ century}

\begin{abstract}
It is our intent to approach to the study of the predominance of Latin literature and language teaching in the nineteenth century in Chile, whose cultural matrix was forged in an intellectual space starting in the 1840s, with a primacy that modulates the educational system up to the 1880 s, a period in which progressively both positivism and philology -with disputes over cultural, political, and even religious issues- displaced the classical humanities model, setting in its place the study of the Spanish Language.

Keyword: literature, education, Latin, Spanish Language, Chilean nineteenth century Chile.

Recibido: 09-05-2012 Aceptado: 12-07-2012

* Este trabajo se inscribe en el marco de la investigación llevada a cabo a partir de la Tesis Doctoral presentada en el año 2009 en la Pontificia Universidad Católica de Valparaíso. La línea de investigación se inscribe en el cruce entre Historia de la Literatura e Historia de la Educación y se vincula al relevamiento de los procesos que marcaron los cambios en la enseñanza de la literatura en Chile en el siglo XIX y primeras décadas del XX.

* Doctora en literatura. Pontificia Universidad Católica de Valparaíso. Chile. edda.hurtado@ucv.cl
\end{abstract}


Del latín al castellano o de las humanidades clásicas a las humanidades modernas en el siglo XIX chileno / Edda Hurtado

En el periodo de fundación del Estado republicano en Chile, tanto la enseñanza de las humanidades clásicas como luego de las modernas, se desarrolló en un escenario de máxima complejidad que demanda interrogarnos acerca de si la influencia francesa consistió en una transferencia cultural, una reproducción meramente imitativa de categorías culturales o una apropiación libre y creativa de un nuevo paradigma cultural exógeno (Conejeros, 1999). En este estudio, nos inclinamos a sostener que el modelo educacional chileno (secundario y universitario de elite) estuvo atravesado por el intento de los intelectuales fundacionales (De Marinis, 2006; Charle, 2000; Dosse, 2006) de fijar las bases de una pedagogía de la ciudadanía en el emergente escenario de incorporación de la nación a la modernidad. El paradigma clásico y luego el moderno tuvieron, en cada momento histórico, como fundamento discursivo, la necesidad de que los conocimientos debían programarse y difundirse a través del sistema educacional y se esperaba que contribuyeran al desarrollo de la ciudadanía. Tanto las Humanidades Clásicas como las Modernas consolidaron en su base una educación moral que se inscribió en las prescripciones curriculares, en los reglamentos de control disciplinario y, en particular, a través de la enseñanza de la lengua y la literatura.

El permanente debate investigativo motivado por la influencia de los aportes provenientes de la historia cultural y la historia del curriculum nos ha permitido conocer los usos que se hicieron del latín en la época moderna y los discursos que se elaboraron en torno de él, su contenido, pero también la voluntad que los animó así como la estrategia que les sirvió de base; reflexiones que nos parecen altamente significativas, por tratarse del desarrollo de las bases del sistema educativo chileno. La productividad de estos discursos operó en un complejo proceso de transferencia cultural que favoreció la legitimación de la emergente oligarquía criolla en el periodo que Carmagnani ha denominado como "la fase inicial de la hegemonía oligárquica, es decir, "[la formación] de una clase cuyos orígenes son coloniales, que [basó] su poder en el control de los factores productivos y que utilizó directamente el poder político para aumentar su dominación sobre las restantes capas sociales" (1984).

La práctica lectora de textos y autores que estaba en el centro de la enseñanza de las humanidades permitía el contacto con las civilizaciones fundadoras de la cultura occidental a través del ejercicio de la traducción, la imitación y la composición que contribuían al desarrollo del gusto, el sentido crítico, la capacidad de juicio personal, el arte de

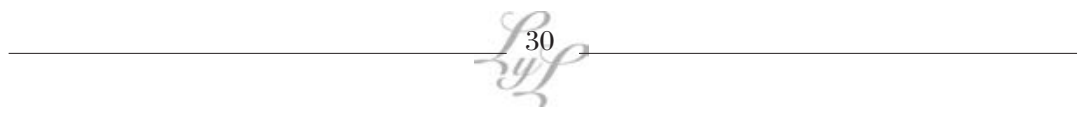


expresarse oralmente y de escribir de acuerdo a las normas recibidas (Chervel, 1997). El prestigio del latín en la época moderna como lengua en uso -aunque restringido- se mantuvo y se trasmitió a las emergentes repúblicas hispanoamericanas a pesar de la tensión que representaba la progresiva legitimación de las lenguas nacionales. En Francia, en los siglos XVII y XVIII, el latín fue fundamentalmente la lengua de la escuela y su vigencia permite designar al siglo XIX como el del "reinado del latín en la enseñanza" vinculado a la perpetuación del modelo humanista de formación y a la reproducción de una distinción social. Más que el conocimiento de una lengua muerta, un ejercicio de razonamiento, fortificación de la memoria o formación del carácter y del gusto fue signo de diferencia y el indicador seguro de una condición superior. La persistencia del latín en el marco de las Humanidades Clásicas alcanzó supremacía más allá de los distintos sistemas políticos y sus respectivas ideologías, posicionándose sólidamente en la base de la cultura de Occidente ${ }^{1}$. En Francia, las finalidades que articulaban la clase de humanidades fueron de carácter cognoscitivo, retórico, religioso y moral, en cuanto eran la ocasión de contribuir a formar el estilo latino en los alumnos, mejorando su conocimiento de la Antigüedad, sus costumbres y la profundización de su fe. Visto así, era imposible que el estudio del latín se constituyera en una "disciplina" regulada por una finalidad propia en el marco de una pedagogía con objetivos estrechamente imbricados: cada texto estudiado, incluidos los textos poéticos u oratorios, eran la ocasión de dar a conocer el pasado antiguo. Los textos históricos contribuían también al mejoramiento del vocabulario y el perfeccionamiento del estilo latino de los alumnos a la par que a su edificación moral. El latín permitía también el desarrollo de la retórica y la oratoria, materia principal para quienes quisieran optar por la vida pública y la política (Douay-Soublin, 1997). El carácter simbólico del latín otorgaba a la vez que demandaba una adhesión a la elite dominante como signo de reconocimiento, lo cual no implicaba un dominio de las lenguas, sino que se esperaba al menos una cierta familiaridad con frases y citas latinas; "las humanidades [eran] en el amplio sentido del término una preparación moral. La enseñanza secundaria tenía por rol 'hacer hombres' y no solamente alumnos de bachiller". Una amplia parte de los textos explicados en clases y los temas de composición propuestos comportaban una carga educativa basada en la observación, el análisis, el estudio del hombre

1 André Chervel y Marie Madeleine Compére, Les Humanités dans l'Histoire de l'Enseignement Francais. Revue Histoire de l'Education, nº 74, mai, 1997:5. 
Del latín al castellano o de las humanidades clásicas a las humanidades modernas en el siglo XIX chileno / Edda Hurtado

en sus relaciones con otros o consigo mismo. Los manuales de latín del siglo XVIII y XIX "agrupaban extractos tales como la prudencia, la justicia, el valor, la moderación, [los cuales] le llevaban a defender e ilustrar "virtudes", "valores", entre los cuales se encontraban la justicia, la moderación, la honradez, la abnegación, etc". (Chervel, 1997:5).

¿Cuánto de esta parte de la historia cultural europea encontró su correlato en el Chile del siglo XIX? Siendo un país que intentaba adscribir culturalmente al proyecto de la Modernidad europea, la validez del Humanismo clásico con su impronta de prestigio permitió el desarrollo de una comunidad intelectual de carácter transversal ${ }^{2}$. Si hacia el siglo XIX en Europa el latín estaba contaminado de "pronunciaciones locales" y la discusión acerca de la continuidad de su prestigio radicaba en su carácter universalizante en cuanto lengua imperial escrita y fuertemente vinculada a la Iglesia, en el Chile decimonónico -en el ámbito de la educación de la elite- el estudio del latín proveyó de una filiación cultural con la más antigua tradición europea, a la vez que neutralizó -al igual que en Europa- las amenazas que provenían de la irrupción de los barbarismos locales y las tensiones lingüísticas provocadas por el rápido ascenso de las denominadas lenguas modernas (francés, inglés y alemán, principalmente), que a su vez comportaban los signos de un proceso de expansión en el marco del desarrollo de la industria cultural.

El estudio del latín en Chile -con carácter obligatorio, desde el siglo XVIII y gran parte del XIX- estuvo presente en la enseñanza secundaria y universitaria desde que la Real Universidad de San Felipe inició sus actividades docentes en 1758. Su vigencia y su pertinencia para la formación de los hijos de las familias de la oligarquía criolla que estudiaban en el Instituto Nacional y en la Universidad de Chile estuvo en directa relación con el desarrollo de un método de estudio, principalmente memorístico y basado en la traducción, orientado hacia un disciplinamiento moral. No se trató -al igual que en Francia- de la conformación de una disciplina de estudios con orientación hacia el conocimiento a través de métodos y objetivos específicos, sino que estos eran trascendentes, por cuanto llevaban consigo como consecuencia

2 Sin olvidar que ese carácter de "transversalidad" se menciona aquí en cuanto caracterizó a todos los integrantes de la República de las Letras o, en palabras de Rama, al anillo letrado que rodeaba el poder; los letrados fueron educados bajo esta preceptiva, más allá de sus adscripciones políticas, liberales o conservadoras, pues estas tensiones y contradicciones emergieron del mismo grupo letrado.

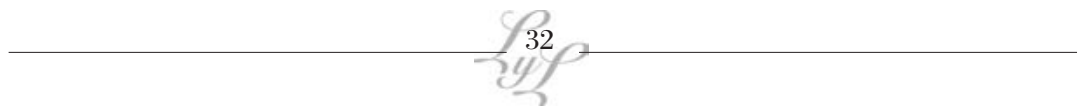


inmediata la distinción cultural de las clases dominantes. Desde este punto de vista, la enseñanza de la lengua y literatura latina en el Chile decimonónico revestía un carácter simbólico al conferir un marco de pertenencia a una elite como signo de distinción (Bourdieu).

\section{Itinerario de las Humanidades Clásicas: la distinción cultural de las elites}

En los momentos iniciales del sistema educativo de enseñanza secundaria en Chile, bajo el proyecto republicano, las discusiones en torno al rol de la educación, y en especial del latín, tuvieron una importante notoriedad. De acuerdo a lo que sostiene Nicolás Cruz, "[el] gobierno republicano chileno se definió tempranamente en una clave conservadora, autoritaria y centralista, reflejando las características más visibles de quienes asumieron la conducción social y política de la Independencia, y especialmente luego de la batalla de Lircay en 1830 (2002) 3". Los gobiernos de la época se centraron en favorecer el desarrollo de la enseñanza secundaria en desmedro o desatención de la educación primaria que prácticamente fue abandonada por los gobiernos republicanos, además no tenía incidencia en la educación superior, quedando a cargo de congregaciones religiosas en su mayoría. El énfasis en la enseñanza secundaria tuvo importantes consecuencias en el desarrollo cultural y social chileno, pues imprimió a la sociedad ciertas características que perduraron hasta bien entrado el siglo XX:

la enseñanza secundaria o media como un tramo escolar con objetivos y contenidos propios se fue diseñando a partir de la Independencia, pero fue a partir del año 1843 que se implementó de manera definitiva a través del llamado Plan de Estudios Humanistas, inspirado por Ignacio Domeyko y con la aprobación de Antonio Varas, Andrés Bello y otros. (Cruz, 2002:20)

El perfil de ese plan destinado a la enseñanza secundaria tuvo una prioridad fundamental en cuanto estaba diseñado y orientado a la for-

3 Nicolás Cruz, El surgimiento de la educación secundaria pública en Chile. 1843- 1876. Santiago: DIBAM, 2002. La importante investigación realizada por este autor nos servirá de base para esta parte de nuestro análisis, pues los datos históricos aparecen claramente delimitados en relación con los hitos más importantes del periodo en que el Plan Humanista estuvo vigente en Chile. Nuestro propósito será profundizar en su contenido histórico, complementándolo con la perspectiva de la enseñanza de la lengua y literatura latinas y sus implicancias en el proyecto educacional. 
Del latín al castellano o de las humanidades clásicas a las humanidades modernas en el siglo XIX chileno / Edda Hurtado

mación de "jóvenes chilenos de sexo masculino y pertenecientes a los grupos acomodados de la capital y ciudades más importantes" (Cruz, 2002), pues eran los que posteriormente participarían en los diversos ámbitos de la sociedad, fueran estos políticos, económicos o administrativos, es decir, eran los futuros hombres letrados que accederían al gobierno de la naciente república. Bastaba la enseñanza secundaria como requisito para el cumplimiento de esas tareas.

En la etapa inicial del Plan Humanista en Chile, destaca la figura de Ignacio Domeyko -científico de origen polaco que se arraigó en Chile y que propugnó importantes debates para la instrucción chilena- y la polémica que este sostuvo con el Ministro Antonio Varas - Ministro de Justicia, Culto e Instrucción Pública. Para Domeyko, el carácter de la enseñanza debía estar orientado hacia el bien moral del país, vale decir, hacia la mantención y consolidación del orden y de las instituciones, junto con

la formación del carácter nacional y el desarrollo progresivo de las inclinaciones más nobles de los habitantes. Sólo una ilustración fundada en los principios de una verdadera religión, y en un sistema de estudio bien arreglado, uniformado en todas partes de la nación, y adaptado a las necesidades morales de todas las clases, [podía] suavizar y mantener en los límites debidos este impulso hacia la libertad y la independencia, tan natural en el hombre. (Domeyko, 1843)

Asimismo, los principios de la educación humanista que regían en Europa también debían organizar ideológicamente a las jóvenes generaciones, a través de la "formación del gusto [...] como aquel destinado a desarrollar nobles sentimientos que permitieran el desarrollo interior de las personas así como las virtudes cívicas". Al respecto, Domeyko sostenía que el estudio de la literatura y de los idiomas antiguos, y en particular del idioma clásico latino, permitían el acceso a la literatura e influía en el espíritu público y el patriotismo de los ciudadanos de una república; "sin el conocimiento del latín y de su gramática, dificulto que alguien aprenda con perfección el castellano y los inmensos recursos que presenta este idioma que se ha formado y perfeccionado sobre el latín" (Cruz, 2002).

4 Ignacio Domeyko, Memoria sobre el modo más conveniente de reformar la instrucción pública en Chile, citado por Cruz en Ob. Cit.: 28.

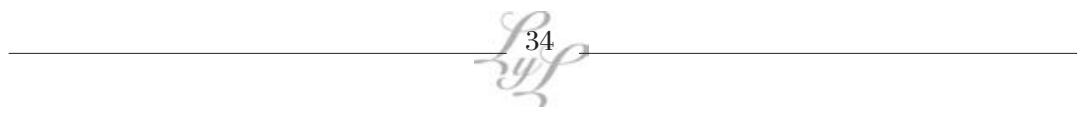


El plan de estudios de $1843^{5}$ tiene una especial importancia debido a que las polémicas que suscitó en la clase dirigente dan cuenta de las principales tensiones que caracterizaron el desarrollo del modelo humanista clásico en Chile. El estudio de la lengua y la literatura latinas ocupaba un lugar central y, si bien comprendía una educación que enfatizaba el aprendizaje y conocimiento de las lenguas latina y griega, esta última no tuvo la misma relevancia. Independiente de la enseñanza de una u otra lengua, lo que quedaba fuera de discusión -y que precisamente fue el tema central de las posteriores polémicas-era la "utilidad" en el dominio de estos conocimientos, pues el énfasis estaba puesto en el sustento teórico del curriculum. La principal característica de este plan era la formación del espíritu a través del control del discurso en tanto los textos de literatura antigua permitían desarrollar cualidades tales como la claridad en el pensamiento y en la expresión, el rigor en la secuencia de las ideas, la preocupación por la mesura y el equilibrio, es decir, la adecuación lo más justa posible entre la lengua y la idea. Esta discusión respecto de la utilidad de la educación portaba los signos que enfrentaban a liberales y conservadores en cuanto a la necesidad de generar un proyecto educativo de mayor integración a nivel nacional y que se orientara en sus bases hacia una formación práctica que contribuyera al desarrollo de las actividades económicas -comercio, agricultura, industria- para las que sin duda el latín no era relevante; por otra parte, "[la] idea que se encontraba muy acentuada era aquella de que la instrucción tenía como finalidad conseguir puestos de trabajo que permitieran a las personas obtener estatus y mejores ingresos". Ante esas dos demandas, tanto en favor de la instrucción elemental como de la profesional, Domeyko "[insistía] en una educación independiente y que contuviera todos los elementos necesarios para la formación integral de la persona" (Cruz, 2002:31). La discusión con relación a este plan de

5 El carácter de la educación secundaria fue el principal tema del periodo, más central que la formación profesional. Uno de los puntos neurálgicos de las polémicas, de las críticas y de las reformas, era que preparaba exclusivamente para las profesiones y más específicamente para la abogacía, dejando a una gran cantidad de estudiantes con una débil formación general, y sin preparación para el trabajo. La reforma llevada a cabo en el Instituto Nacional en 1843, impulsada por Antonio Varas e Ignacio Domeyko, pretendía darle sentido en sí misma a la educación secundaria, ampliando las materias de enseñanza -humanistas y científicas- con el fin de que preparara para otras profesiones además de leyes y diera una sólida formación general para cualquier desempeño laboral. Si bien la reforma de 1843 tuvo logros en la ampliación de los estudios, éstos siguieron fuertemente orientados hacia las profesiones, como indica el hecho de que al ingresar al Instituto Nacional, entre los 9 y los 13 años, el estudiante debía optar por el curso de humanidades que conducía a leyes y medicina, o al de matemáticas, que conducía a las ingenierías. Sol Serrano, Universidad y Nación. Santiago, Ediciones Universitarias, 1993: 155 y ss. 
Del latín al castellano o de las humanidades clásicas a las humanidades modernas en el siglo XIX chileno / Edda Hurtado

estudios se centraba en la necesidad de establecer "una tríada educacional que [consistiera] en entender la instrucción orientada hacia el desarrollo de la voluntad (la religión), el raciocinio (las matemáticas) y el gusto (las humanidades)", lo que plantea una diferencia de fondo que tiene importantes consecuencias para el estudio del latín en los colegios"; esta diferencia -según Cruz- descansaba en el tercer elemento de la tríada, vale decir, en el desarrollo del gusto, el cual Varas consideraba que era indispensable desarrollar.

Las humanidades, en su orientación clásica, eran el camino a través del cual se entregaba toda aquella instrucción que se requería para un desempeño personal y social que a través de las sucesivas reformas quedó radicalmente cuestionada pues no respondía a la necesidad educacional de la mayoría de quienes asistían a los liceos chilenos. Luego de esta polémica, se impone el Plan Humanista impulsado por Domeyko, el que también contó con la aprobación de Diego Barros Arana y de Andrés Bello, quien asignaba por objetivo a la educación la formación de ciudadanos virtuosos, los que a través de la literatura latina podían asimilar ejemplos de virtuosismo y política conjugados en el momento de apogeo de la república romana, importante paradigma educativo para las nacientes repúblicas hispanoamericanas. La demandas por los estudios útiles, que comienzan a surgir en las provincias, tensionarán el lugar exagerado de la enseñanza de la lengua latina y tomará mayores proposiciones desde fines de la década de 1850 e inicios de la siguiente.

La polémica sobre la enseñanza del latín en la escuela secundaria en Chile comienza en 1857 con Gregorio Víctor Amunátegui, quien propone quitarle al latín su carácter de obligatoriedad,

"dejándolo sólo para aquellos que [quisieran] perfeccionar sus conocimientos literarios". A cambio del latín proponía incluir el francés, inglés y alemán. En 1863, Joaquín Larraín Gandarillas (quien más tarde participará en la fundación de la Universidad Católica de Chile), en su incorporación a la Universidad de Chile, defiende la vigencia del latín. En 1865, Benjamín Vicuña Mackenna, propone una comisión que revise la importancia del latín para la obtención del grado de Bachiller en Humanidades ${ }^{6}$.

6 En esta polémica se destacan las figuras de: José Larraín Gandarillas, Diego Barros Arana, Benjamín Vicuña Mackenna, Gregorio Víctor y Miguel Luis Amunátegui, Guillermo Matta, Domingo Santa María y Justo Florian Löbeck. En 1865, la Universidad de Chile decide mantener el carácter de obligatoriedad para el latín.

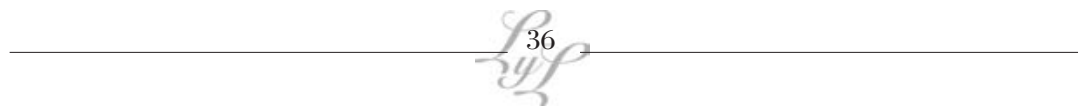


Gregorio Víctor Amunátegui señalaba que el latín era una lengua muerta cuyo estudio demandaba un gran esfuerzo por parte de los estudiantes y que no reportaba grandes beneficios; admitía que el conocimiento de las lenguas modernas podía significar un mayor beneficio a una nación en formación a la vez que favorecería el ingreso en un mundo moderno ${ }^{7}$. El debate ideológico que acompañó a los contendores se dividía al menos en dos posturas opuestas. Por un lado, y como una corriente más minoritaria, estaba Benjamín Vicuña Mackenna, para quien la enseñanza del latín era considerada como una herencia directa de la Colonia y por lo tanto un signo del sometimiento. Una segunda generación de intelectuales, entre los que encontramos a Guillermo Matta, Alberto Blest Gana, luego Diego Barros Arana, fue educada bajo la preceptiva latina. Sin embargo, la discrepancia que sostenían se refería hacia la atención que el Estado otorgaba a la enseñanza del latín en un contexto en el que la población requería otra orientación en los estudios. Estas polémicas a la larga fueron desplazando al latín de la enseñanza secundaria, sin desaparecer del todo, ya que seguiría siendo un sello de distinción de los círculos letrados. Gradualmente se fueron incluyendo modificaciones a pesar de la insistencia de su enseñanza por parte de la Facultad de Filosofía y Humanidades. En 1863, se lleva a cabo otra importante reforma, cuyo propósito era consolidar la educación secundaria. Si bien conservaba en esencia los postulados del Plan Humanista de 1843, ampliaba el conocimiento de las ciencias, fortaleciendo la formación previa a la especialización profesional y "[revertía] la tendencia de alumnos y padres a considerar la educación como un conjunto de requisitos que había que cumplir en el menor tiempo y al menor costo posible para alcanzar un título profesional" (Serrano, 1993: 156):

7 En 1858 la Facultad de Humanidades nombró una comisión para reformar el programa. [...] se propuso crear un cuerpo de ramos comunes para todos los estudiantes y luego cursos especiales que prepararan para el desempeño laboral o profesional: latín para abogados y médicos, curso científico de matemáticas para ingenieros y un curso comercial con elementos de química y agricultura para quienes no aspirasen a un título. La proposición fue apoyada por el Ministerio, pero no se llevó a cabo y sólo se abrieron algunos cursos sueltos como el de teneduría de libros. Dichas proposiciones fueron consideradas en la segunda reforma general del programa promulgada en 1863 [...] mantenía la división de los cursos de humanidades y matemáticas, pero disminuía la diferencia entre ambas áreas. Profundizaba el estudio de las ciencias exactas en las humanidades al hacer obligatorios los cursos de geografía, física, química, historia natural y cosmografía. Se agregaba también el curso de historia de la filosofía y de la literatura. La reforma establecía el orden en que debían rendirse los exámenes, reformaba los textos de estudio y los métodos pedagógicos y designaba profesores especializados para las asignaturas superiores. El gran impulsor de esta reforma fue Diego Barros Arana en su calidad de Rector del Instituto Nacional. Sol Serrano, Op. Cit., p. 156-157. 
Del latín al castellano o de las humanidades clásicas a las humanidades modernas en el siglo XIX chileno / Edda Hurtado

La tensión entre educación general y profesional, así como entre la formación teórica y práctica también se hizo presente en la polémica del latín. Generalmente, se olvida señalar que, al tratar esta polémica, que el latín era sólo obligatorio para el bachillerato en humanidades, requisito para el ingreso a leyes y medicina, el argumento central de los detractores del latín [fue] que su estudio no tenía utilidad práctica mientras sus defensores sostenían que formaba la inteligencia a la vez que era indispensable para la literatura de ambas profesiones. (158)

Con la reforma del Instituto Nacional de 1863, se uniformó la enseñanza secundaria en los liceos, se fortaleció una educación humanistacientífica y se establecieron los cursos superiores para optar a títulos profesionales; este plan no estuvo exento de dificultades en su implementación, sobre todo en provincias, dada la falta de recursos por parte del Estado, así como el poco interés de los profesionales de la capital por trasladarse a provincias a ejercer la docencia. El carácter centralizado de la educación se mantuvo por largo tiempo. En $1876^{8}$ se decide que el latín no tendrá carácter obligatorio sino optativo y en 1880 desaparece definitivamente de los planes de estudio (Labarca, 1939). En tiempos del presidente Balmaceda (hacia fines de la década de 1880) se reorganizará la educación secundaria, contratando profesores alemanes para los colegios y para el Instituto Pedagógico dependiente de la Facultad de Filosofía de la Universidad de Chile -fundado en 1889- donde se formarán los profesores destinados a ejercer la docencia secundaria.

\section{De las humanidades clásicas a las humanidades modernas}

Las críticas al latín se inscribieron en el periodo que va desde la década de 1870 que, según Ángel Rama, correspondió a la inauguración de una segunda prueba para la ciudad letrada en un escenario en el que el

8 Según afirma Amanda Labarca, "la década pedagógica de 1870 comienza con la lucha por el predominio del estado docente (es decir, la educación impulsada por el Estado, quien asigna recursos, diseña políticas educacionales y crea la institucionalidad clave para la administración del sistema); termina con la promulgación de la ley de 1879 que moderniza y reforma las enseñanzas superior y media. [...] En ella se ventilan por primera vez y se discuten apasionadamente problemas como la enseñanza secundaria femenina. A medida que el elemento liberal conquista el poder, el ritmo de innovación se acelera, hasta que el estallido bélico contra el Perú y Bolivia señala un alto brusco, una detención que será un recoger de fuerzas para hacer más intenso el impulso reformador de la post-guerra. Amanda Labarca, Historia de la Enseñanza en Chile, Santiago, 1939:137.

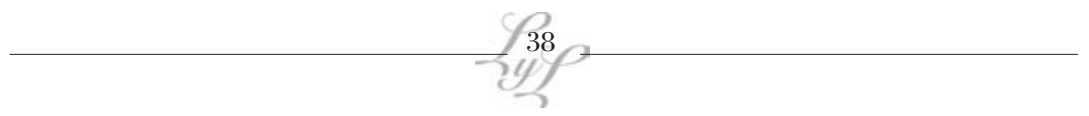


desarrollo del circuito letrado se volvió más complejo y controversial. Esta ampliación del "anillo letrado" en torno al poder coincide con lo que Carmagnani ha denominado como la segunda fase de la oligarquía: el proceso de consolidación y de ingreso en una economía de cuño capitalista. En el ámbito educacional, Amanda Labarca se refiere a este periodo como el de "Nuevas Orientaciones", en el que se destaca la diversificación de las influencias bajo el contexto de las políticas implementadas durante el gobierno de Federico Errázuriz entre los años 1871 y 1876, periodo en el que las posiciones más moderadas acordaron reducir el estudio de las lenguas clásicas y promover la autonomía progresiva del estudio de la gramática castellana. Ante quienes no se proponían modificar ni el objeto ni los métodos de enseñanza, surgieron también los partidarios de una formación de tipo científico, que inspiró el modelo de enseñanza que se instauró a fines de siglo, bajo la organización de una pedagogía de corte positivista. Estas tensiones enmarcadas en el cuestionamiento al "espacio tradicional de la ciudad letrada" fueron expresadas por emergentes intelectuales críticos que arremetieron contra una clase conservadora que se había replegado principalmente en las universidades y que producía y reproducía una ideología anquilosada en viejas tradiciones. El lugar ideológicamente central que el latín había alcanzado en el sistema educacional chileno fue directamente vinculado con los discursos, las prácticas religiosas y la ideología cultural conservadora, producto de los cuestionamientos provenientes de Europa, donde la capacidad del latín como espacio discursivo y disciplinario había disminuido en cuanto a la promoción de articulaciones "políticamente productivas con otras formas de práctica social, y debió ceder su lugar y su importancia educativa, política y cultural, al recién creado Castellano". Asimismo, Poblete afirma que los ataques al latín no pueden ser separados de las luchas políticas por secularizar la sociedad chilena y por afirmar el poder del Estado por sobre el de la institución eclesiástica. En este sentido,

la defensa del latín fue tanto un asunto político como pedagógico y educativo, [por lo tanto] habría una conexión fuerte y no simplemente metafórica entre el desarrollo del Estado chileno y el castellano como materia escolar. El triunfo y la implantación del Castellano como metadisciplina que agrupó los restos útiles de varias otras consideradas ahora residuales, no hace sino manifestar performativamente, en sí mismo y con independencia de los contenidos literarios del currículum, el triunfo del Estado, de su racionalidad y de la lengua estandarizada en que dicha racionalidad decide expresarse. (Poblete, 2002: 215) 
Del latín al castellano o de las humanidades clásicas a las humanidades modernas en el siglo XIX chileno / Edda Hurtado

La instauración del castellano como nueva disciplina de estudio fue la culminación de un proceso mayor relacionado con el desarrollo de un proyecto de nación que se inscribía en la modernidad ${ }^{9}$, un proceso más general de modernización económica incipiente "con sus consiguientes corolarios de desarrollo de las fuerzas productivas, especialización de la labor intelectual y complejización de las funciones burocráticas". Este espacio protomoderno, que Poblete vincula a las ciudades "patricias", entró en el proceso de democratización de la ciudad letrada que entre sus principales factores destacó la "amenaza de descentramiento lingüístico producida por la inmigración extranjera, complicada sobre todo por la influencia francesa". Frente a estas amenazas surgieron las Academias de la Lengua que proporcionaron un contingente capacitado de lingüistas que, hacia fines del siglo XIX, favorecerán el impulso de los estudios filológicos, cuya expresión más importante en Chile es la influencia alemana y los aportes académicos de Rodolfo Lenz.

La ciencia como instrumento con el que se podría dominar la naturaleza era la idea subyacente en el concepto de educación que sostenían las posiciones secularizantes que confiaban en el progreso como expresión del orden. Hacia la década de 1880, la evolución pedagógica en general, con la promoción de la enseñanza primaria y de la enseñanza superior con una Universidad de tipo moderno puso también en entredicho un modelo que tenía claras dificultades para encontrar en sí mismo las fuentes de su renovación. Hacia fines de siglo, el monopolio de las humanidades clásicas en la enseñanza secundaria dio paso a la enseñanza de las denominadas humanidades modernas y las materias que tradicionalmente se

9 Bajo el Gobierno de Santa María, en 1883, se ordenó la construcción de edificios para la enseñanza primaria, la contratación de profesores para las escuelas normales y la salida de maestros chilenos a estudiar al extranjero; junto con ello, se adquirió mobiliario, útiles de enseñanza y libros para las bibliotecas; asimismo, viajan normalistas a perfeccionarse en el extranjero y se contrata un contingente de maestros alemanes, que introdujeron nuevos métodos, levantaron el nivel científico y el aprecio público por la profesión. "El 4 de febrero del año siguiente, se comisionó a don José Abelardo Núñez para trasladarse de nuevo a Europa, contratar profesores, adquirir material de enseñanza y determinar en qué institutos harían sus estudios los primeros cinco normalistas chilenos agraciados por las becas. Estos primeros normalistas son: José Tadeo Sepúlveda, Juan Madrid, José María Muñoz Hermosilla, Emiliano Figueroa y Carlos Bosche. [...] En marzo de 1885, principiaron a llegar a Chile los primeros contratados alemanes y en el mismo año don José Abelardo Núñez abrió al público la exposición de material escolar, en su mayor parte elegido por él mismo en las fábricas europeas. Los beneficios de la influencia se recogen en la modernización de los métodos, en la introducción de algunas asignaturas y en el mayor énfasis concedido a otras. Los perjuicios más visibles de su actuación se palpan en la extranjerización del espíritu de la enseñanza, su alejamiento de la realidad autóctona, en su concepto aristocrático y monárquico de la disciplina». Labarca, Ob. Cit., 182

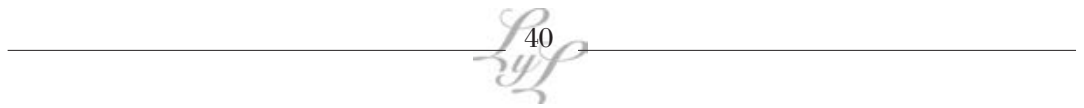


enseñaban bajo el rótulo de "humanidades clásicas" se distribuirán hasta bien avanzado el siglo XX en las distintas "disciplinas literarias". Entre 1860 y 1912 se desarrollaron hitos importantes, reformas e innovaciones que apuntan a la búsqueda de la cientificidad educacional: la dictación de la Ley Orgánica de Instrucción Primaria 1860 y el Congreso de Enseñanza Secundaria de 1912. Las transformaciones en este periodo se articulan en torno al impulso renovador que pretendía asentar la educación sobre bases teóricas y prácticas respaldadas por concepciones científicas del hombre y de la sociedad. La articulación de este impulso se realizó en el marco del positivismo heredado por Augusto Compte, "quien desde su prisma planteaba una perspectiva eminentemente científica, que también demandaba de la educación una jerarquía más orgánica y consecuente con la idea de progreso indefinido, idea asentada en la elite chilena desde la década de 1880" (Celis, 1998). Sin duda que en este periodo la sociedad chilena se enfrentó al ejercicio de una autonomía que implicó la conformación del Estado y la elaboración de un proyecto que determinó su ingreso periférico a la modernidad. Ello redundó en el desarrollo de una institucionalidad marcada por una incipiente economía y una estructura social que tuvo a Europa como modelo. La consolidación de la revolución industrial a la par que el surgimiento de nuevas expresiones artísticas y culturales que allá surgieron fueron cambios importantes que condicionaron el desarrollo de las emergentes naciones latinoamericanas que miraban a Europa con el deseo de reproducir aquellas significativas transformaciones. En Chile, el Estado se fundó sobre una sólida base institucional y un respaldo legislativo fundamental con "el que estableció un ejecutivo centralizado y fuerte, dirigiendo con eficiencia a la nación al mantenerla unida e incorporarla a los modelos culturales y políticos predominantes en Occidente" (87). Sin embargo, este periodo también se caracterizó por debates educacionales que cuestionaron el rol hegemónico del Estado tanto en la educación pública como en el papel regulador y centralizado en relación a la enseñanza privada, que estaba a cargo de las congregaciones católicas; no obstante, "la educación privada mantuvo siempre una importante presencia y en forma muy especial, los colegios católicos velaron por ampliar su autonomía y debilitar la presencia del Estado en las orientaciones del sistema (88)". Los debates de fondo confrontaban a liberales y conservadores, quienes a su vez representaban la tensión entre el Estado y la Iglesia Católica. En el plano de la enseñanza se jugaban los idearios que propugnaban o un modelo de educación humanista o uno de orientación científico positivista. Los representantes de las instituciones más conservadoras de la sociedad tuvieron en la defensa del latín su más explícito emblema. Las iniciativas 
Del latín al castellano o de las humanidades clásicas a las humanidades modernas en el siglo XIX chileno / Edda Hurtado

más significativas del periodo -la ley de Educación Secundaria de 1879, la creación del Instituto Nacional en 1889, los congresos de educación de 1889, 1902 y 1912- fueron canales de discusión en torno a la defensa de una orientación humanista enfrentada al arrollador avance de las nuevas tendencias del positivismo.

\section{La Reforma de 1893. La nueva pedagogía positivista}

A la influencia del modelo de enseñanza francés, le siguió un nuevo ideario educacional derivado del impulso que Alemania había alcanzado en Europa luego de la guerra entre Francia y Prusia. En el Chile de fin de siglo, el liberalismo comenzó a debilitarse como fuerza política, llegando en 1891 a dividirse; las ideas liberales e ilustradas siguieron en cambio ganando adeptos en el plano cultural y a nivel de la sociedad civil. La modernización económica en marcha y la diversificación social exigían urgentes reformas educativas. En este nuevo escenario se reactivó el interés por la educación y el progreso, pretensiones que en la última década permearon -con tintes laicos y positivistas- incluso a las agrupaciones y partidos populares.

Un hito fundamental, una bisagra entre dos momentos de la historia de Chile en el siglo XIX fue, sin duda, la revolución de 1891, aunque lo principal no estuvo en la revolución propiamente tal, sino esencialmente en los sucesos que ocurrieron en torno al evento militar. Si consideramos la crisis del gobierno de Balmaceda como un hito para distinguir un antes y un después en el reordenamiento de los distintos actores sociales -representantes de la antigua oligarquía y sectores emergentes-, el periodo posrevolucionario correspondió a la consolidación de la hegemonía oligárquica. Esta segunda fase, a su vez, tiene su límite en el año 1914, con la crisis del salitre. En el fondo, se perfilan dos modelos de nación distintos: uno antiguo que venía de los años 30, cercano a la iglesia y de tinte conservador y otro, secular, pragmático y cientificista en sus enfoques que corresponde al punto de partida de la masificación de la educación; el surgimiento del nuevo proyecto cultural se expresó a través de una crítica a la extranjerización, que más apareció en el discurso que en los hechos, puesto que, en el gobierno de Balmaceda, se otorgaron importantes garantías a capitales extranjeros. El eje de los grupos "post revolución del "91" correspondió a una nueva representación de la oligarquía, una renovación que marcó el ingreso de este sector en un proceso de consolidación de su proyecto hegemónico. Si la oligarquía adscribía al sector conservador, en el periodo post su representación

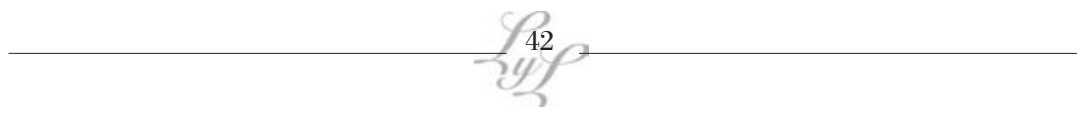


política se amplió, renovando su discurso educacional con la incorporación de modelos educativos de influencia alemana y posteriormente -ya entrado el siglo XX-de los modelos educacionales provenientes de Suecia y de Norteamérica.

Las repercusiones más importantes en el plano educacional se hicieron sentir en la profesionalización docente a través de la fundación del Instituto Pedagógico en 1889, proyecto que responde en gran medida al esfuerzo de Valentín Letelier, quien fue comisionado a Alemania y además es considerado como el principal forjador de una pedagogía positivista en Chile. Las variadas gestiones gubernamentales por modernizar la organización del sistema educacional se expresaron en la presencia de profesores alemanes provenientes del ámbito de la filología y de los estudios clásicos. Valentín Letelier en "La lucha por la Cultura" (1895) se refiere a la fundación del Instituto Pedagógico como una obra del Gobierno de Balmaceda, creado como institución dependiente de la Universidad de Chile. Los primeros profesores del Instituto fueron: Don Jorge Enrique Schneider (Filosofía y Pedagogía); don Juan Steffen (Historia y Geografía); Federico Hansen (Filología); Reinaldo von Lilienthal (Matemáticas); Alfredo Beutell (Ciencias Físicas); Federico Johow (Ciencias Naturales). Además de ellos, encontramos a don Enrique Nercasseaux y Morán, chileno, que tenía a su cargo la enseñanza de la literatura española y americana (Amanda Labarca, 1930:186); una de las consecuencias más significativas fue la implantación del Plan Concéntrico ${ }^{10}$ en 1893. La influencia de los profesores alemanes significó la gran reforma de la educación media. Los planteamientos pedagógicos de Herbart que se sustentaban en la valorización de la formación del carácter y el logro de la virtud personal a través del método científico al igual que el método de Pestalozzi tuvieron gran influencia en el desarrollo de las ideas pedagógicas de este nuevo proyecto. Producto de ello, las nuevas propuestas sobre educación incorporaron a la familia y la escuela, atribuyéndole a esta última un rol cada vez más importante. El postulado era que la

10 A. Labarca se refiere a D. Pedro Montt, en 1886, quien "al presentar al Consejo Universitario el proyecto de creación de la Escuela Normal Superior, sugería la abolición del sistema de estudiar asignaturas completas y sucesivas por el de agrupar los ramos que pertenezcan a un mismo orden de conocimientos, de manera que su estudio empiece en el primer año del curso y continúe con desarrollo progresivo hasta concluir el sexto. La reforma abarcaba la estructura del plan y los métodos, puesto que se quería implantar la didáctica herbatiana, preconizada por los profesores germánicos. Se realizó, a pesar de la resistencia de la Facultad y de gran número de profesores del Instituto Nacional. El Consejo Universitario, y sobre todo don Diego Barros Arana, persistieron en su empeño, cuyo fruto fue el decreto de 10 de enero de 1889 , en virtud del cual se ordenó ensayar un plan concéntrico, por lo menos en algunos liceos de la República". Op. Cit., p. 197. 
Del latín al castellano o de las humanidades clásicas a las humanidades modernas en el siglo XIX chileno / Edda Hurtado

escuela instruía y civilizaba, liberaba a los ciudadanos de la superstición y del dogmatismo, lo cual instaló la polémica entre las escuelas laicas y las de congregaciones religiosas.

En 1893, en la publicación oficial de los Programas destinados a la enseñanza secundaria ${ }^{11}$ de los establecimientos nacionales, el Consejo de Instrucción Pública señalaba "que la lei [los] ha colocado bajo la inspección universitaria" y aclaraba que se trataba de una nueva reforma "solo de método" donde lo central era sustituir la enseñanza de ramos aislados, independientes unos de otros, por otra simultánea de todos los ramos a la vez; la estructura del plan concéntrico planteaba la enseñanza de una asignatura que partía de nociones básicas que se ampliarían gradualmente cada año "en proporción al desarrollo intelectual de los alumnos". El propósito era que el orden de los contenidos fuera más variado, más práctico y ameno y el método se fundamentaba en la repetición continua de las lecciones, para que los alumnos "conserven mejor los conocimientos que con el antiguo sistema solían y podían olvidar mas o menos jeneralmente después de cada examen" (9), criticando con esta afirmación el antiguo plan humanista. Esta innovación de método, procuraba el desenvolvimiento gradual de las nociones científicas y literarias que se dictaban en los cursos de instrucción secundaria. Entre las dificultades que esta reforma planteaba estaba la de hacer una adecuada distribución de las partes o nociones de cada ramo que debían enseñarse de año en año. Para ello, la experiencia de los profesores era fundamental; se consideraba que debían tener un conocimiento profundo del área y de la "pedagojía moderna". Este proyecto fue impulsado por los profesores del Instituto Pedagógico. Los nuevos programas "consistían en cuestionarios ordenados de las materias de cada ramo, cuyo apredizaje era exijido a los alumnos; i en este sentido servían para preparar sus exámenes respectivos (11)". Otro alcance importante era que estos nuevos programas estaban destinados a los profesores a los cuales se les daba junto con los contenidos algunas indicaciones metodológicas para favorecer la enseñanza.

La reforma de 1893 a la enseñanza secundaria bajo el modelo cientificista o positivista en el que se inscribieron las Humanidades modernas, instauró las bases de la enseñanza secundaria y la disciplina Castellano, con el modelo de enseñanza literaria desde la perspectiva historiográfica, se mantuvo sin grandes variaciones hasta la reforma curricular actualmente vigente llevada a cabo en la década de 1990.

11 Plan de Estudios. Programas de Instrucción Secundaria. Aprobados por el Consejo de Instrucción Pública para los Liceos del Estado. Santiago de Chile: Imprenta Cervantes, 1893: IX y ss.

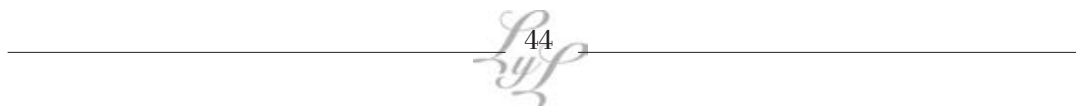




\section{Bibliografía}

Anales de la Universidad de Chile: años 1846- 1900.

Carmagnani, Marcello. Estado y Sociedad en América Latina, 1850-1930. Barcelona: Editorial Crítica, 1984.

Celis, Luis; Guzmán, Andrés; Pozo, José M. Educadores Ilustres en la historia educacional chilena. Siglos XVIII- XX. Santiago de Chile: Publicaciones de la Facultad de Educación de la Pontificia Universidad Católica de Chile, 1998.

Conejeros M., Juan P. La influencia cultural francesa en la educación chilena, 1840-1880. Santiago: Universidad Católica Cardenal Raúl Silva Henríquez. Serie Investigación, 1999.

Cruz, Nicolás. El surgimiento de la educación secundaria pública en Chile. 18461876. El plan de estudio humanista. Santiago de Chile: Centro de Investigaciones Diego Barros Arana, 2002.

Chervel, André. Les Humanités Classiques. Revue Histoire de l'education, $n^{\circ} 74$, mai 1997.

Plan de estudios i programas de instrucción secundaria aprobados por el Consejo de Instrucción Pública para los liceos del Estado. Santiago de Chile: Imprenta Cervantes, 1893.

De Marinis, Pablo. "Los saberes de expertos y el poder de hacer y deshacer sociedad", en Meeting of the Latin American Studies Association, San Juan, Puerto Rico, Marzo 15-18.

Douay-Soublin, Françoise. «Les recueils de discours français pour la classe de rhétorique», en Revue Histoire de l'Education, n 74 , Francia: I.N.R.P.: 1997:151-185.

Goodson, Ivor. Historia del Currículum. La construcción social de las disciplinas escolares. Barcelona: Ediciones Pomares - Corredor, S.A., 1995.

Labarca, Amanda. Historia de la enseñanza en Chile. Santiago de Chile: Imprenta Universitaria, 1939.

Lenz, Rodolfo. Proyecto de Programa de Castellano. $1^{\circ}$ a $6^{\circ}$ Humanidades. Santiago de Chile: 1899.

Letelier, Valentín. La lucha por la cultura. Miscelánea de artículos politicos y estudios pedagógicos. Santiago de Chile: Imp. Barcelona, 1895. 
Del latín al castellano o de las humanidades clásicas a las humanidades modernas en el siglo XIX chileno / Edda Hurtado

Poblete, Juan. Literatura chilena del siglo XIX: entre públicos lectores y figuras autoriales. Santiago: Editorial Cuarto Propio, 2002.

Serrano, Sol. Universidad y Nación. Chile en el siglo XIX. Santiago de Chile: Editorial Universitaria, 1994. 